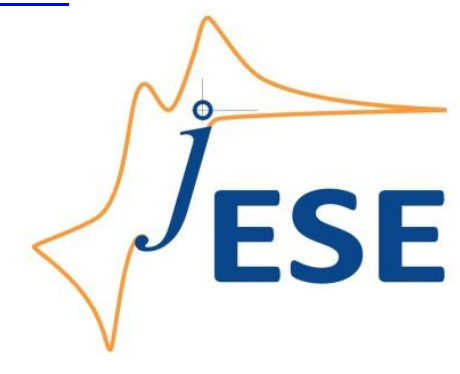

Open Access : : ISSN 1847-9286

www.jESE-online.org

Original scientific paper

\title{
Electrochemical behaviour of electrodeposited Pd and PdNi coatings for the ethanol oxidation reaction in alkaline solution
}

Jelena D. Lović ${ }^{凶}$, Vladimir D. Jović ${ }^{1}$

ICTM, Department of Electrochemistry, University of Belgrade, Njegoševa 12, 11000, Belgrade, Serbia

${ }^{1}$ Institute for Multidisciplinary Research, University of Belgrade, Kneza Višeslava 1, 11030, Belgrade, Serbia

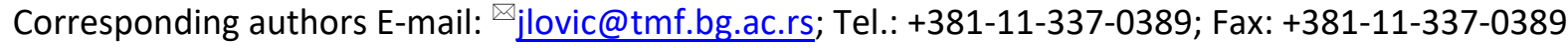

Received: September 19, 2017; Accepted: October 25, 2017

\begin{abstract}
Electrodeposited Pd and PdNi coating samples were tested for ethanol oxidation reaction (EOR) in alkaline solution using cyclic voltammetry (CV), chronoamperometric (CA) and quasi steady-state measurements. All alloy samples showed higher current densities for the EOR than pure Pd coating. The current density increased with increasing the amount of Pd in the PdNi coating and the most active one was found to be Pd0.74NiO.26. Based on CA measurements a pseudo-steady state is achieved after $1500 \mathrm{~s}$ showing that Pd0.74Ni0.26 is more efficient and poisoning more tolerant than other investigated coatings. Upon the end of the current-time transient, the investigated catalysts were subjected to the potential cycling showing the ability to recover activity loss implying the surface composition stability of binary coatings.
\end{abstract}

Keywords

Palladium; Nickel; Stability

\section{Introduction}

Among the different types of fuel cells, direct alcohol fuel cells possess besides high energy densities, low pollutant emissions and low operating temperatures $\left(60-100^{\circ} \mathrm{C}\right)$ [1-3]. Alkaline direct ethanol fuel cells (ADAFCs) is recognized as promising power source because ethanol has higher energy density and lower toxicity compared to methanol [4]. Anode catalysts with high catalytic activities as well as good poison resistances are of great significance to the commercialization of ADAFCs. For alcohol oxidations, Pd-based nanocatalysts are superior to Pt-based catalysts in alkaline media and are widely used as anode catalysts in ADAFCs $[1,5]$. 
For the sake of commercialization, the activity and stability of pure Pd needs improvement which could be achieved by combining Pd with other metals or metal oxides. It has been reported that modifications of the Pd nanocatalyst by metals such as $\mathrm{Ni}[6-8], \mathrm{Au}[9,10], \mathrm{Cu}[10,11], \mathrm{Ag}[10,12], \mathrm{Co}$ $[10,13]$ effectively improve the catalytic performances of the $\mathrm{Pd}$ nanocatalyst toward alcohol oxidations in alkaline media.

Nickel has been used to modify anode catalysts due to its high electrochemical stability in alkaline media and the low cost. Nickel-modified Pd electrodes have been reported as catalysts with excellent performances in ethanol oxidation reaction (EOR) such as the activity, the low overpotentials and the improved poison resistances. Examined parameters of EOR such as onset potential reaction and long-term stability show that among a series of graphene (G)-supported $\mathrm{Ni}_{x} \mathrm{Pd}_{100-x}$ binary alloyed catalysts, $\mathrm{Ni}_{50} \mathrm{Pd}_{50} / \mathrm{G}$ catalyst exhibits $60 \mathrm{mV}$ lower onset potential compare to $\mathrm{Ni}_{0} \mathrm{Pd}_{100} / \mathrm{G}$ catalysts and current density approximately 8,4 , and 1.7 times superior than that of $\mathrm{Ni}_{75} \mathrm{Pd}_{25}, \mathrm{Ni}_{0} \mathrm{Pd}_{100} / \mathrm{G}$, and $\mathrm{Ni}_{25} \mathrm{Pd}_{75} / \mathrm{G}$ catalysts, respectively [6]. The mass activity of the $\mathrm{Pd}_{83} \mathrm{Ni}_{17}$ hollow nanospheres aerogel is 5.6-fold higher than that of the commercial Pd/C catalyst [14] while the mass activity of porous bimetallic $\mathrm{PdNi}$ catalyst is 3.5 times higher compared to the commercial $\mathrm{Pd} / \mathrm{C}$ [15]. It is revealed that the onset potential is $\sim 80 \mathrm{mV}$ lower and the peak current is about 3 times higher for ethanol oxidation using multi-walled carbon nanotubes (MWCNT) catalysts with $\mathrm{Pd}_{1} \mathrm{Ni}_{1.5}$ compared to those of $\mathrm{Pd} / \mathrm{MWCNTs}$ due to the small particle size and high crystallinity of binary catalyst [16] although it can be found that binary $\mathrm{Pd}_{3.7} \mathrm{Ni}_{1}$ nanocatalyst with ultra-low loading of metals immobilized on MWCNT exhibits anodic current density over 11 times higher than on the $\mathrm{Pd} / \mathrm{MWCNT}$ [17]. The electro-catalytic activity of the carbon nanofibers (CNF) supported Pd-Ni nanoparticles prepared by chemical reduction with $\mathrm{NaBH}_{4}$ was examined for EOR show that the onset potential was $200 \mathrm{mV}$ lower and the peak current density 4 times higher compared to that for $\mathrm{Pd} / \mathrm{C}$ as a result of the uniform distribution of metal nanoparticles on the CNF support while the significant increase in reaction kinetics was achieve by raising the temperature to $60{ }^{\circ} \mathrm{C}$ [7]. Negatively shifted onset potential and doubled peak current density in potentiodynamic measurements for core-shell Ni-Pd/C compared to $\mathrm{Pd} / \mathrm{C}$ was found [18], while high activity and excellent stability during continuously cycling were found for Pd supported on Ni foam [19,20].

It was proposed that the ligand and strain effects contribute the enhanced activity of Pd in the presence of $\mathrm{Ni}$. Namely the insertion of smaller $\mathrm{Ni}$ atoms into the $\mathrm{Pd}$ crystal lattice causes a contraction of the Pd lattice. This causes a downshift of the Pd d-band center and consequently leads to weaker bonding with adsorbates such as poisoning intermediates in the EOR. Besides, Pd has a higher ionization energy than $\mathrm{Ni}$ and because of that $\mathrm{Ni}$ atoms become positively charged, facilitating the formation of oxides on $\mathrm{Ni}[21,22]$. Generated $\mathrm{OH}_{\mathrm{ad}}$ species of $\mathrm{Ni}$ participate in the oxidative desorption of intermediates in the EOR enhancing the activity of binary PdNi catalysts.

The electrochemical methods for the preparation of metal alloy nanoparticles are extensively developed topic in materials science. In order to increase the activity and durability physical properties such as composition of the alloys, structure and the size of nanoparticles are carefully selected. Most of the synthesis methods use organic surfactants, capping agents or high temperatures, consequently heating or cleaning treatment are necessary and therefore, the catalytic activity can be affected by undesirable adsorbed species. Nevertheless, among the various methods, electrodeposition is recognized as a simple and versatile method to prepare bimetallic surfaces. Several methods for PdNi alloy electrodeposition can be find in the literature such as: doublepotential step electrodeposition technique from the solution containing $\mathrm{NiSO}_{4}, \mathrm{H}_{2} \mathrm{PdCl}_{4}$ and $\mathrm{Na}_{2} \mathrm{SO}_{4}$ [23]; cathodic deposition from the solution containing $\mathrm{PdCl}_{2}, \mathrm{H}_{2} \mathrm{SO}_{4}, \mathrm{NH}_{4} \mathrm{Cl}$ and $\mathrm{NiCl}_{2}$ using hydrogen 
dynamic bubble template producing three-dimensional hierarchical pores of intercomnected dendrite walls [24]; electrodeposition in the presence of complexing agent, ethylenediamine $[25,26]$; electrodeposition from a ionic liquid as electrolyte $[16,27]$; physical vapour deposition which was used to obtain palladium-modified nickel foam material [19].

The aim of this work is to investigate the electrochemical behavior of electrodeposited $\mathrm{Pd}$ and $\mathrm{PdNi}$ coatings for the EOR in $1 \mathrm{M} \mathrm{NaOH}$ at room temperature. An attempt is made to estimate the difference in catalytic activity of binary coatings in comparison with the Pd coating toward EOR, to test the stability of PdNi coatings and their ability to recover activity loss. In addition, kinetic and mass transport properties of the electrodeposited coatings are examined.

\section{Experimental}

All experiments were carried out with an VoltaLab PGZ 402 (Radiometer Analytical, Lyon, France) at room temperature in three compartment electrochemical glass cells with Pt wire as the counter electrode and saturated calomel electrode (SCE) as the reference electrode. A mirror-like polished gold rotating disk electrode $(d=5 \mathrm{~mm})$ prepared as described elsewhere [28] served as working electrode. All the solutions used were prepared with high purity UV water (Millipore, $18.2 \mathrm{M} \Omega \mathrm{cm}$ resistivity) and p.a. grade chemicals (Merck). The electrolytes were purged with purified nitrogen prior to each experiment.

Electrodeposition of $\mathrm{PdNi}$ coating samples was achieved galvanostatically on the rotating $\mathrm{Au}$ disc electrode from the plating bath composed of $0.01 \mathrm{M} \mathrm{PdCl}_{2}+0.6 \mathrm{M} \mathrm{NiCl}_{2}+2 \mathrm{M} \mathrm{NH}_{4} \mathrm{Cl}$ while pure $\mathrm{Pd}$ was electrodeposited from the bath containing $0.05 \mathrm{M} \mathrm{PdCl}_{2}+2 \mathrm{M} \mathrm{NH}_{4} \mathrm{Cl}$. All the conditions are the same as it was described in [29].

The electrochemically active surface area (ECSA) was estimated from the charge corresponding to the $\mathrm{Pd}$-oxide reduction peak in $1 \mathrm{M} \mathrm{NaOH}$ by dividing obtained charge with the charge of $420 \mu \mathrm{C} \mathrm{cm}^{-2}$ (corresponding to the monolayer of $\mathrm{Pd}$-oxide), in accordance with the previous reports $[6,8,22]$. The presented results are corrected for the ECSA.

Behavior of electrodeposited $\mathrm{Pd}$ and $\mathrm{PdNi}$ samples during the investigation of the EOR was recorded in the solution containing $1 \mathrm{M} \mathrm{C}_{2} \mathrm{H}_{5} \mathrm{OH}+1 \mathrm{M} \mathrm{NaOH}$ by using $\mathrm{CV}$ and polarization measurements at $1000 \mathrm{rpm}$. For current density-time responses of EOR the potential was stepped from $800 \mathrm{mV}$ to $-400 \mathrm{mV}$.

\section{Results and discussion}

\section{Electrochemical characterization of the electrodeposited samples}

The CVs of the investigated binary coatings and pure Pd coating in $1 \mathrm{M} \mathrm{NaOH}$ are displayed in Fig. 1. Anodic linear sweep voltammetry (ALSV) analysis and the energy dispersive X-ray spectroscopy (EDS) were used for the determination of the alloy coatings composition giving following compositions: $\mathrm{Pd}_{0.74} \mathrm{Ni}_{0.26}, \mathrm{Pd}_{0.50} \mathrm{Ni}_{0.50}$ and $\mathrm{Pd}_{0.28} \mathrm{Ni}_{0.72}$ [29]. The $\mathrm{CV}$ s presented in Fig. 1 clearly indicate that the current densities for hydrogen adsorption-absorption/desorption and oxide formation and reduction are higher for PdNi samples than those recorded on the CV for pure Pd coating. Reduction of Pd-oxide on all catalysts creates a well-defined peak, but at different potentials. On PdNi coatings the peak maximum is shifted towards more negative potentials compared to pure $\mathrm{Pd}$ coating, which indicates a stronger adsorption of oxide species on the surface of bimetallic coatings due to the presence of $\mathrm{Ni}$ [8]. It was shown that the formation of a monolayer of the $\alpha-\mathrm{Ni}(\mathrm{OH})_{2}$ occurred in the potential region between $-1000 \mathrm{mV}$ and $-700 \mathrm{mV}$, while at potentials more positive than $200 \mathrm{mV}$ further oxidation of $\mathrm{Ni}(\mathrm{II})$ species into $\mathrm{NiOOH}$ occurs [30]. 
Hence, the formation and the reduction of $\mathrm{Ni}(\mathrm{OH})_{2}$, as well as partial formation of the $\mathrm{NiOOH}$ increase the anodic current density at potentials more positive than $100 \mathrm{mV}$ as is presented in Fig. 1. Also, these processes occurred simultaneously with the formation and reduction of Pd-oxide.

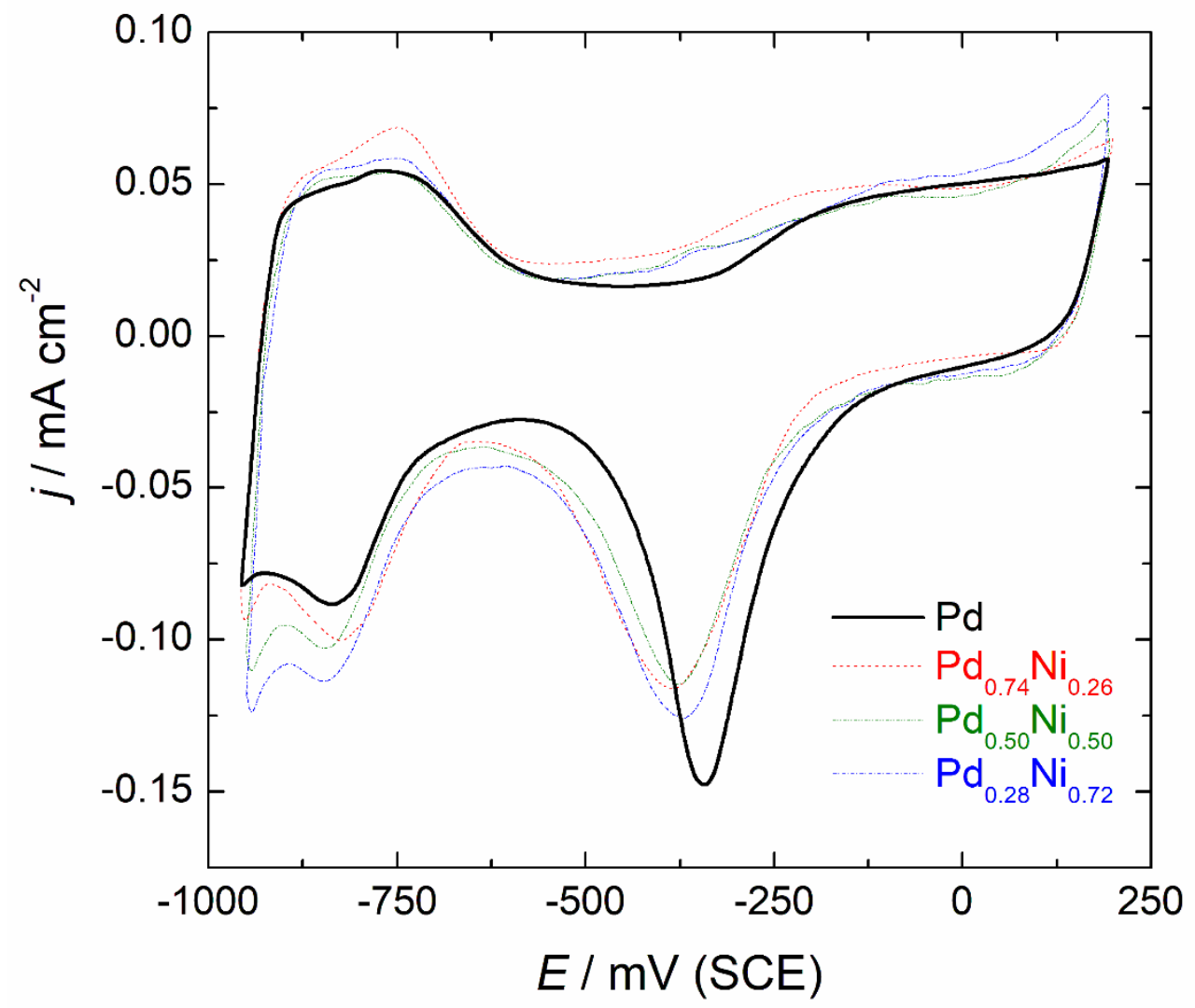

Figure 1. CVs recorded with the scan rate $50 \mathrm{mV} \mathrm{s}^{-1}, 1000 \mathrm{rpm}$ on Pd and PdNi coatings in $1 \mathrm{M} \mathrm{NaOH}$.

\section{The EOR}

The activity of the $\mathrm{Pd}_{0.74} \mathrm{Ni}_{0.26}, \mathrm{Pd}_{0.50} \mathrm{Ni}_{0.50}, \mathrm{Pd}_{0.28} \mathrm{Ni}_{0.72}$ and $\mathrm{Pd}$ coatings for the EOR in alkaline medium was investigated by the CV (Fig. 2). Considering electrochemical behavior of pure Pd during the EOR it was suggests that the carbonaceous intermediates can be strongly adsorbed on the Pd surface blocking the activity in the forward scan up to $\sim-650 \mathrm{mV}[31,32]$. Since the Pd begins to adsorb $\mathrm{OH}^{-}$species in the region of hydrogen adsorption [23], strongly adsorbed carbonaceous species can be oxidized, causing the increase of current density of the forward peak. Surface oxide formation block further adsorption of reactive species leading to decrease of current density of the forward peak. In the backward scan, the reduction of surface oxides enables ethanol adsorption at the free Pd surface, so that EOR current densities in the backward peak ascend. The peak in the backward scan could be assigned to the elimination of carbonaceous species that are not completely oxidized in the forward scan [23].

Among the CVs for the EOR at PdNi coating samples presented in Fig. 2, the current density increased with the increase of $\mathrm{Pd}$ content up to 74 at.\%. Also, it seems that the small amount of $\mathrm{Ni}$ is sufficient to shift the reaction onset potential to more negative values since EOR on $\mathrm{Pd}_{0.74} \mathrm{Ni}_{0.26}$ starts $\sim 50 \mathrm{mV}$ earlier compared to the other binary coatings and $\sim 100 \mathrm{mV}$ compared to the $\mathrm{Pd}$ coating. It was demonstrated based on the ratio of the forward and the backward peak current density that the alloy surfaces were less poisoned than pure Pd coating [29]. Among them the $\mathrm{Pd}_{0.74} \mathrm{Ni}_{0.26}$ coating is the most poisoning tolerant. The role of $\mathrm{Ni}$ in binary coatings can be rationalized in following way: since $\mathrm{Ni}$ itself is not active for the EOR at the potentials relevant for 
the practical application [33] the presence of $\mathrm{Ni}$ in the PdNi alloy enhance the EOR by increasing the presence of $\mathrm{OH}$ species at the electrode surface $[6,8,17]$ leading to the shift of onset potential to more negative values and the increase of the current density, as observed in Fig. 2. Also, the presented results reveal better utilization of $\mathrm{Pd}$ on the surface of $\mathrm{Pd}_{0.74} \mathrm{Ni}_{0.26}$ coating due to appropriate surface morphology since more active sites are accessible to the EOR. It can be pointed out that improved catalytic activity of investigated binary coatings can be achieved through the optimization of the Ni content and appropriate surface morphology.

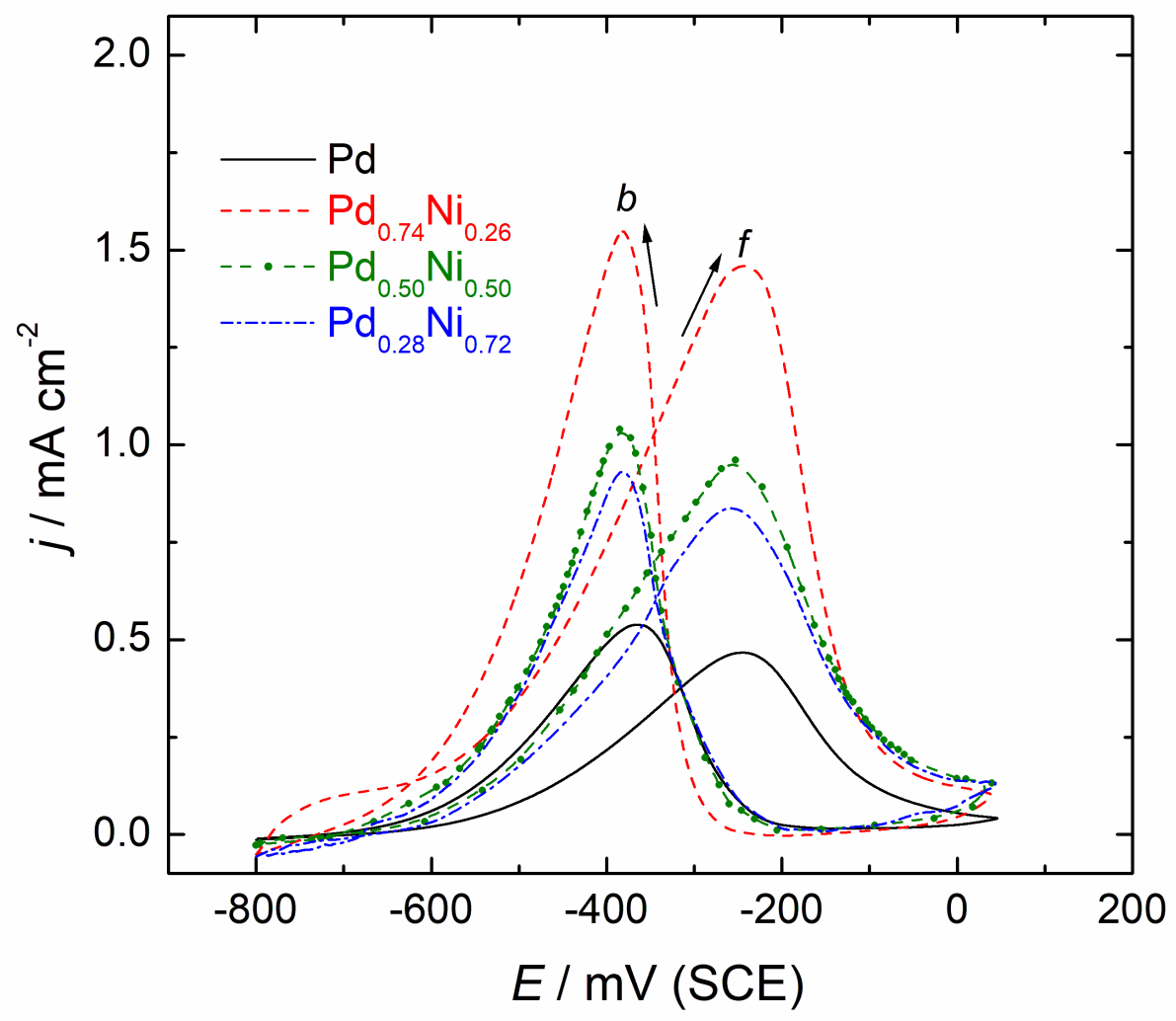

Figure 2. CVs recorded with the scan rate $50 \mathrm{mV} \mathrm{s}^{-1}, 1000 \mathrm{rpm}$ on Pd and PdNi coatings in $1 \mathrm{M}$ $\mathrm{NaOH}+1 \mathrm{M} \mathrm{C}_{2} \mathrm{H}_{5} \mathrm{OH}$.

Considering the literature, it can be stated that the best ratio of $\mathrm{Pd}$ and $\mathrm{Ni}$ for the EOR vary, depending on several factors as was explained in [29] whereby excess Ni decrease the activity for EOR due to the active surface blocking [6,35]. It can be found that carbon supported PdNi catalyst with atomic ratio of 40:60 synthesized by the simultaneous reduction method using $\mathrm{NaBH}_{4}$ as reductant exhibits 2 times higher activity and better stability than does the $\mathrm{Pd} / \mathrm{C}$ catalyst [34]. Also the optimized carbon supported PdNi catalyst synthesized through a modified solution phase-based nanocapsule method, with atomic ratio of 44:56 represents the promising anode catalyst for alkaline DEFCs giving $180 \mathrm{mV}$ more negative EOR onset potential and the 33 times higher exchange current density than $\mathrm{Pd} / \mathrm{C}$ [35]. Graphene supported PdNi catalyst prepared by chemical reduction method, with atomic ratio of 50:50 showed the lower onset potential on CV and better long-term stability on amperometric measurements of EOR in a series of investigated binary alloyed $\mathrm{Ni}_{x} \mathrm{Pd}_{100-x} / \mathrm{G}$ catalysts [6].

Chronoamperometric technique is an effective method to evaluate the electrocatalytic activity and stability of catalyst materials. Figure 3 shows the typical current density-time responses of three PdNi coatings and pure Pd coating for the EOR at $E=-400 \mathrm{mV}$. The oxidation current densities rapidly decrease in first $\sim 100 \mathrm{~s}$, likely due to the formation of intermediates and poisoning species 
during the EOR. With the time, a pseudo-steady state is achieved. After a polarization of $1500 \mathrm{~s}$, the investigated electrodes reached their steady-state current densities which are shown in the inset of Fig. 3 with respect to $\mathrm{Pd}$ content (at \%). It can be seen that the current density of the EOR on $\mathrm{Pd}_{0.74} \mathrm{Ni}_{0.26}$ electrode is higher than those on other electrodes, as found above in the CV measurements.

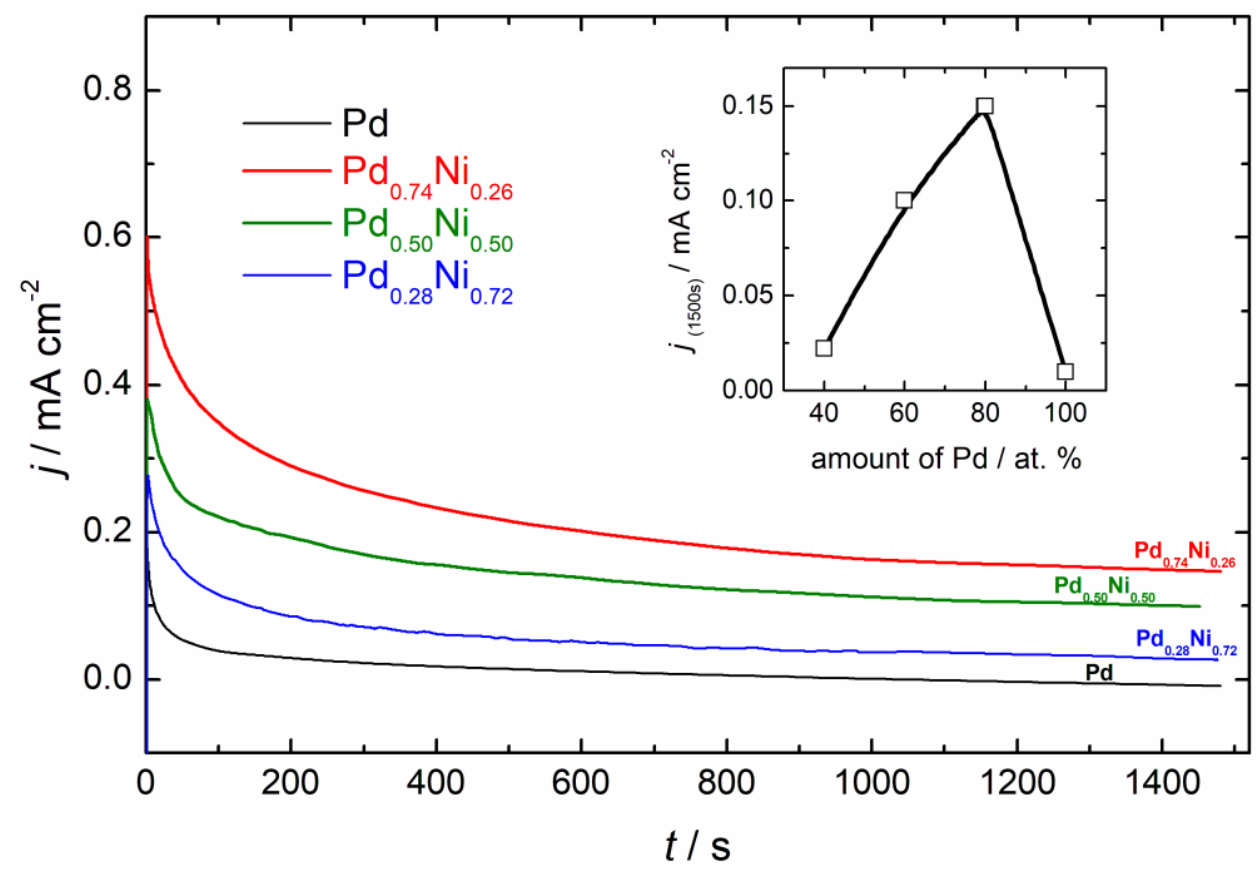

Figure 3. Current density-time responses recorded on Pd and PdNi coatings in $1 \mathrm{M} \mathrm{NaOH}+1 \mathrm{M}$ $\mathrm{C}_{2} \mathrm{H}_{5} \mathrm{OH}$ at $\mathrm{E}=-400 \mathrm{mV} .1000 \mathrm{rpm}$. Inset: current densities after $1500 \mathrm{~s}$ vs. at \% Pd.

Upon the end of the current-time transient, the investigated catalysts were subjected to the potential cycling. Figure 4 depicts the 1 . and 10 . cycles of $\mathrm{Pd}_{0.74} \mathrm{Ni}_{0.26}$ electrode as the representative ones. This PdNi coating shows reduced current densities at the beginning of cycling after CA with further increase of the activity during the cycling. The ability to recover activity loss demonstrates surface composition stability of investigated binary coatings. Hence, PdNi coatings showed enhanced electrocatalytic activity towards EOR which nominates this type of catalyst for possible practical application.

For the purpose of comparing the kinetic and mass transport properties of the investigated electrodes during ethanol oxidation, Tafel polarization analysis and the relation between the peak current density and the scan rate were provided. The Tafel plots are showed in Fig. 5 . The slope of $\sim 140 \mathrm{mV} \mathrm{dec}^{-1}$ for $\mathrm{Pd}_{0.74} \mathrm{Ni}_{0.26}$ is obtained for the potentials up to $-600 \mathrm{mV}$, while $\sim 160 \mathrm{mV} \mathrm{dec}^{-1}$ for $\mathrm{Pd}_{0.50} \mathrm{Ni}_{0.50}, \mathrm{Pd}_{0.28} \mathrm{Ni}_{0.72}$ and $\mathrm{Pd}$ are Tafel slops also obtained at the beginning of the peak in potential window up to $\sim-550 \mathrm{mV}$. Lower Tafel slope indicate faster EOR charge-transfer kinetics. The results of the Tafel polarization study corroborate the findings of CV. Nearly the same values of Tafel plots were obtained on graphene supported NiPd binary catalysts [6], binary composite films of Pd and $\mathrm{Ni}$ on multiwalled carbon nanotubes (MWCNT) [36], carbon supported PdNi nanoparticles [35,37] and rather higher on PdNi nanoparticles supported on sulfonated MWCNT [38].

Figure 6 shows the $\mathrm{CV}$ s obtained at $\mathrm{Pd}_{0.74} \mathrm{Ni}_{0.26}$ catalyst in $1 \mathrm{M} \mathrm{NaOH}+1.0 \mathrm{M} \mathrm{C}_{2} \mathrm{H}_{5} \mathrm{OH}$ solution at different scan rates. The relation between the peak current density obtained from forward CV scan and $v^{0.5}$ of $C V$ is shown in the inset. It can be seen that the oxidation potential and peak current density for ethanol oxidation become larger with the increasing of scan rate. 


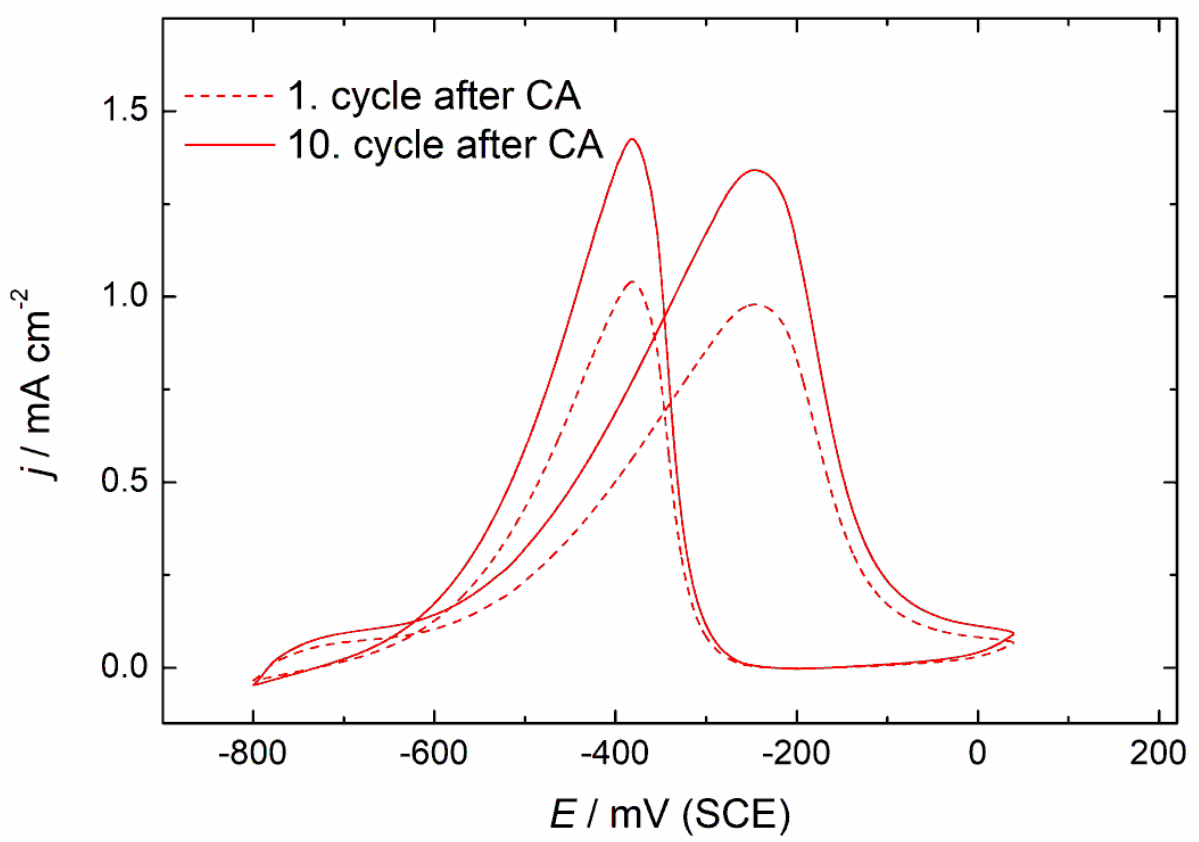

Figure 4. $\mathrm{CVs}$ (1. and 10. cycle) recorded on $\mathrm{Pd}_{0.74} \mathrm{Ni}_{0.26}$ after $\mathrm{CA}$ in $1 \mathrm{M} \mathrm{NaOH}+1 \mathrm{M} \mathrm{C}_{2} \mathrm{H}_{5} \mathrm{OH}$. Scan rate $50 \mathrm{mV} \mathrm{s}^{-1}, R P M=1000$.

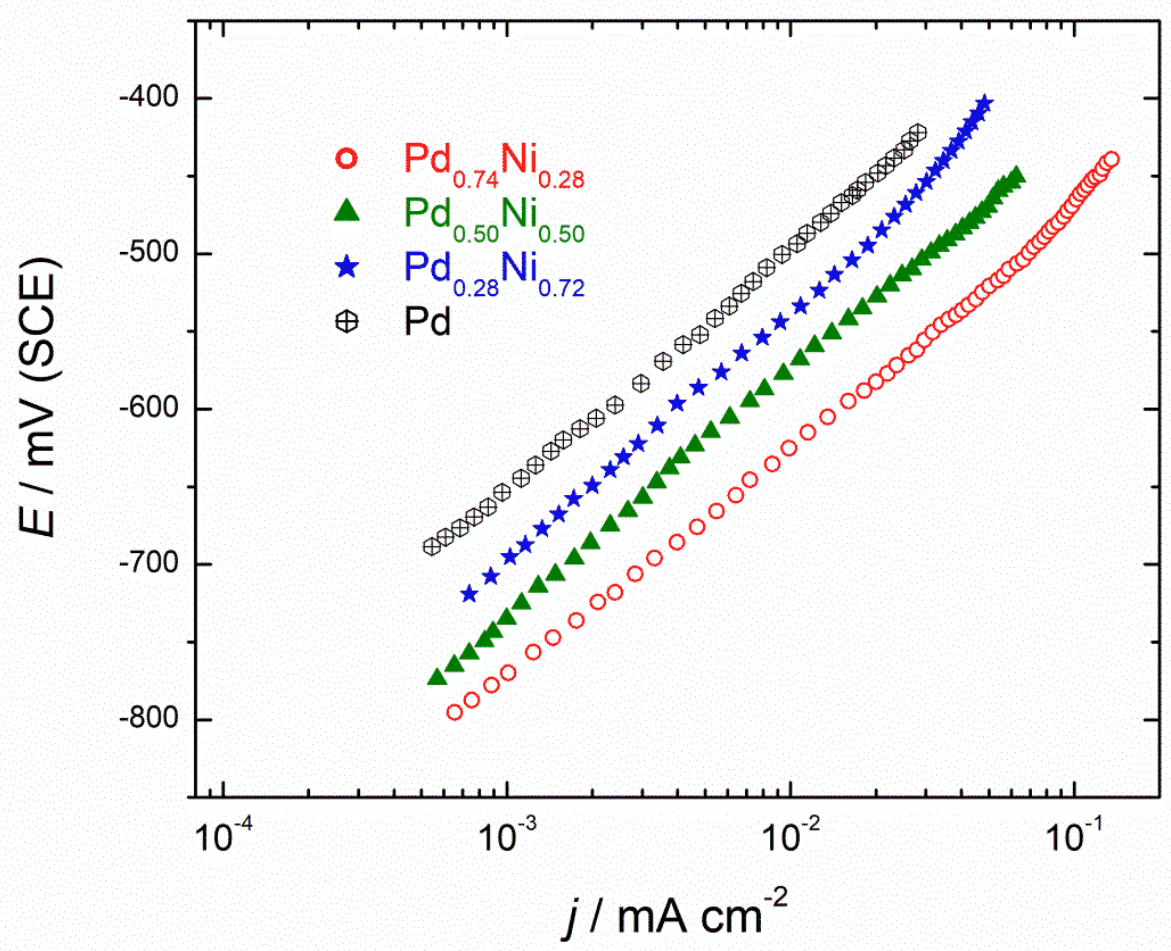

Figure 5. Tafel responses recorded on $\mathrm{Pd}$ and PdNi coatings in $1 \mathrm{M} \mathrm{NaOH}+1 \mathrm{M} \mathrm{C}_{2} \mathrm{H}_{5} \mathrm{OH}$. Scan rate $1 \mathrm{mV} \mathrm{s}^{-1}, R P M=1000$.

The peak current densities in the forward scan are linearly proportional to the square root of scan rates (Fig. 6a). Close inspection of Fig. 6a depict nonzero intercept of the peak current at zero scan rate suggesting that it not is a pure diffusion controlled process. Nonzero intercept could suggest the involvement of some type of surface interactions in examine reaction. Additionally, the peak potential in the forward scan $\left(E_{\mathrm{pa}}\right)$, increase with the increase of $v$, and a linear dependency can be obtained between $E_{\mathrm{pa}}$ and $\ln v$, as shown in Fig. $6 \mathrm{~b}$. The same dependency was obtained on 
pure Pd coating and binary coatings with higher content of $\mathrm{Ni}$ indicating that the oxidation of ethanol is an irreversible electrode process [6].

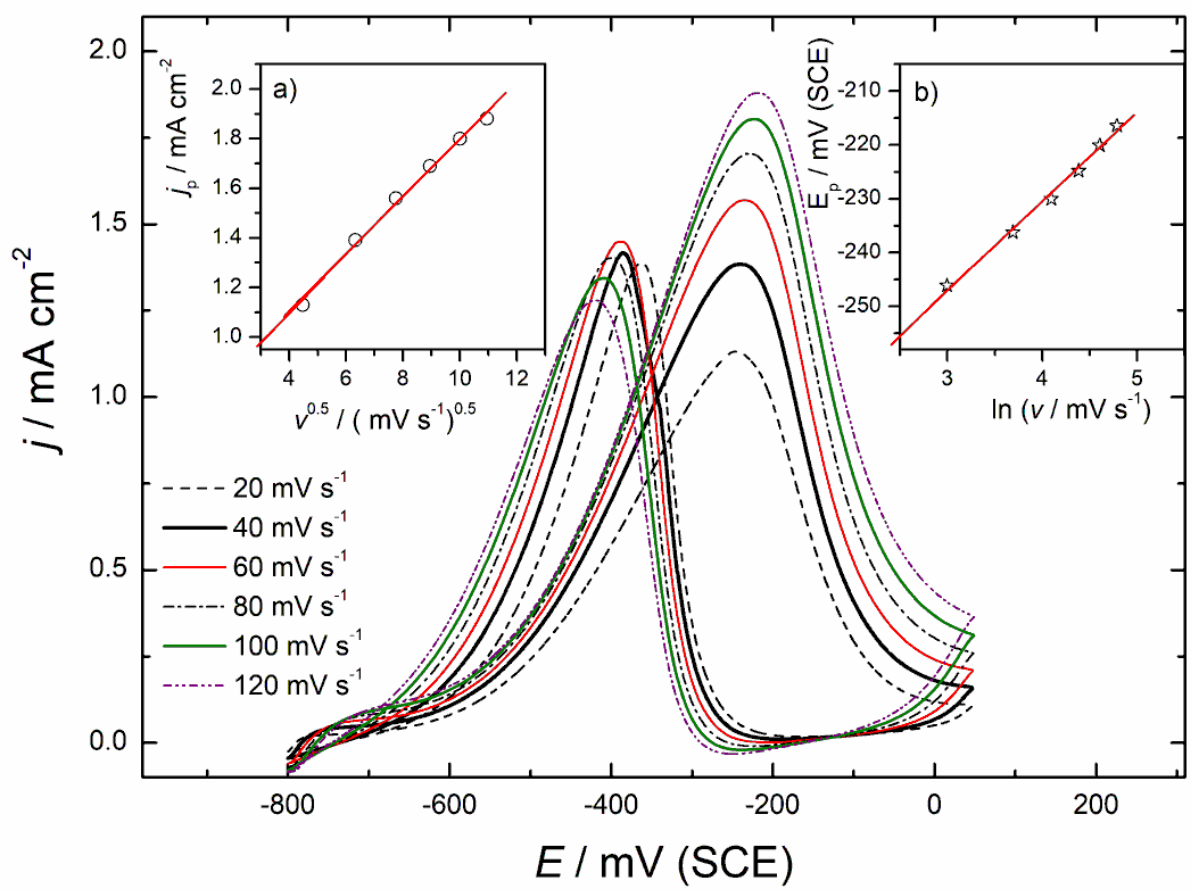

Figure 6. $\mathrm{CVs}$ on $\mathrm{Pd}_{0.74} \mathrm{Ni}_{0.26}$ coating in $1 \mathrm{M} \mathrm{KOH}+1 \mathrm{M} \mathrm{C}_{2} \mathrm{H}_{5} \mathrm{OH}$ at various scan rates. Insets: plots current densities in the forward scan vs. $v^{0.5}(a)$ and peak potentials in forward scan vs. In of scan rates (b).

\section{Conclusions}

In summary, the coating samples obtained by simultaneous electrodeposition were tested for the EOR using CV, CA and quasi-steady state measurements and compare to pure Pd coating. The most active one was found to be $\mathrm{Pd}_{0.74} \mathrm{Ni}_{0.26}$ exhibiting also negatively shifted onset potential for the EOR. Kinetic and mass transport properties reveal lower Tafel slope obtained on $\mathrm{Pd}_{0.74} \mathrm{Ni}_{0.26}$ indicating faster EOR charge-transfer kinetics while the EOR is not a pure diffusion controlled process. Furthermore, it was shown that EOR is an irreversible electrode process on all examined coatings. It was pointing out that $\mathrm{Pd}_{0.74} \mathrm{Ni}_{0.26}$ coating is more efficient and the more poisoning tolerant than the other investigated coatings. Also, the ability to recover activity loss confirms the surface composition stability of investigated binary coatings.

Acknowledgements: This work was financially supported by the Ministry of Education, Science and Technological Development of the Republic of Serbia, Contract No. H-172060.

\section{References}

[1] E. Antolini, E. R. Gonzalez, Journal of Power Sources 195 (2010) 3431-3450.

[2] L. F. Dong, R. R. S. Gari, Z. Li, M. M. Craig, S. F. Hou, Carbon 48 (2010) 781-787.

[3] A. Brouzgou, A. Podias, P. Tsiakaras, Journal of Applied Electrochemistry 43 (2013) 119-136.

[4] S. Song, W. Zhou, Z. Liang, R. Cai, G. Sun, Q. Xin, V. Stergiopoulos, P. Tsiakaras, Applied Catalysis B: Environmental 55 (2005) 65-72.

[5] Y. Wang, S. Zou, W-B Cai, Catalysts 5 (2015) 1507-1534.

[6] M. S. Ahmed, S. Jeon, ACS Catalysis 4 (2014) 1830-1837.

[7] T. Maiyalagan, K. Scott, Journal of Power Sources 195 (2010) 5246-5251.

[8] M. D. Obradovic, Z. M. Stancic, U. C. Lacnjevac, V. V. Radmilovic, A. Gavrilovic-Wohlmuthere, V. R. Radmilovic, S. Lj. Gojkovic, Applied Catalysis B: Environmental 189 (2016) 110-118. 
[9] C. Peng, Y. Hu, M. Liu, Y. Zheng, Journal of Power Sources 278 (2015) 69-75.

[10] K. Persson, A. Ersson, K. Jansson, N. Iverlund, S. Järås, Journal of Catalysis 231 (2005) 139-150.

[11] P. Mukherjee, P. Sarathi, K. Mandal, D. Bhattacharjee, S. Dasgupta, S. Kumar, Electrochimica Acta 154 (2015) 447-455.

[12] S. Fu, C. Zhu, D. Du, Y. Lin, ACS Applied Materials and Interfaces 7 (2015) 13842-13848.

[13] F.I. Pires, H.M. Villullas, International Journal of Hydrogen Energy, 37 (2012) 17052-17059.

[14] B. Cai, D. Wen, W. Liu, A-K. Herrmann, A. Benad, A. Eychmîller, Angewandte Chemie 54 (2015) 1310113105.

[15] Y. Feng, D. Bin, B. Yan, Y. Du, T. Majima, W. Zhou, Journal of Colloid and Interface Science 493 (2017) 190-197.

[16] K. Ding, H. Yang, Y. Cao, C. Zheng, S. B. Rapole, Z. Guo, Materials Chemistry and Physics 142 (2013) 403-411.

[17] Q. Yi, Q. Chen, Electrochimica Acta 182 (2015) 96-103.

[18] M. Zhang, Z. Yan, J. Xie, Electrochimica Acta 77 (2012) 237-243.

[19] T. Mikolajczyk, M. Turemko, B. Pierozynski, Journal of Electroanalytical Chemistry 735 (2014) 32-35.

[20] W. Wang, Y. Yang, Y. Liu, Z. Zhang, W. Dong, Z. Lei, Journal of Power Sources 273 (2015) 631-637.

[21] B. Hammer, J.K. Nørskov, Advances in Catalysis 45 (2000) 71-129.

[22] A. Dutta, J. Datta, Journal of Materials Chemistry A 2 (2014) 3237-3250.

[23] C. Qiu, R. Shang, Y. Xie, Y. Bu, C. Li, H. Ma, Materials Chemistry and Physics 120 (2010) 323-330.

[24] R. Li, H. Mao, J. Zhang, T. Huang, A. Yu, Journal of Power Sources 241 (2013) 660-667.

[25] K. Kumar, H. Haridoss, S.K. Seshadri, Surface and Coatings Technology 202 (2008) 1764-1770.

[26] Q. Yi, F. Niu, L. Sun, Fuel 111 (2013) 88-95.

[27] H. Y. Huang, P. Y. Chen, Talanta 83 (2010) 379-385.

[28] J. Mirković, J. Lović, M. Avramov Ivić, D. Mijin, Electrochimica Acta 137 (2014) 705-713.

[29] J. D. Lović, V. D. Jović, Journal of Solid State Electrochemistry 21 (2017) 2433-2441.

[30] M. Grden, K. Klimek, A. Czerwinski, Journal of Solid State Electrochemistry 8 (2004) 390-397.

[31] L. P. R. Moraes, B. R. Matos, C. Radtke, E. I. Santiago, F. C. Fonseca, S. C. Amico, C. F. Malfatti, International Journal of Hydrogen Energy 41 (2016) 6457-6458.

[32] Z. Liu, X. Zhang, L. Hong, Electrochemistry Communications 11 (2009) 925-928.

[33] T. G. Nikiforova, O. A. Datskevich, V. V. Maleev, Russian Journal of Applied Chemistry 85 (2012) 18711878.

[34] S. Y. Shen, T. S. Zhao, J. B. Xu, Y. S. Li, Journal of Power Sources 195 (2010) 1001-1006.

[35] Z. Zhang, L. Xin, K. Sun, W. Li, International Journal of Hydrogen Energy 36 (2011) 12686-12697.

[36] R. N. Singh, A. Singh Anindita, Carbon 47 (2009) 271-278.

[37] A. Dutta, J. Datta, Journal of Physical Chemistry C 116 (2012) 25677-25688.

[38] T. Ramulifhoa, K. I. Ozoemenaa, R. M. Modibedia, C. J. Jafta, M. K. Mathe, Electrochimica Acta 59 (2012) 310-320.

(C2017 by the authors; licensee IAPC, Zagreb, Croatia. This article is an open-access article distributed under the terms and conditions of the Creative Commons Attribution license (http://creativecommons.org/licenses/by/4.0/) 